\title{
Paralabral cysts in the hip joint: findings at MR arthrography
}

\author{
Olaf Magerkurth • Jon A. Jacobson • \\ Gandikota Girish • Monica Kalume Brigido • \\ Asheesh Bedi • David Fessell
}

Received: 18 September 2011 / Revised: 20 January 2012 / Accepted: 26 February 2012 / Published online: 21 March 2012

(C) ISS 2012

\begin{abstract}
Purpose The purpose of this research was to retrospectively characterize paralabral cysts of the hip as seen at MR arthrography.

Materials and methods After Institutional Review Board approval, 704 patients who had MR arthrography were identified over a 3-year period and 40 patients were identified as having a cyst or fluid collection at the hip by MR report. MR images from these 40 patients were retrospectively reviewed by three radiologists where 18 were found to have a paralabral cyst, which were characterized as follows: location, configuration, contrast filling, size of the cyst, extent, direction, and whether associated osseous changes were present. In addition, the acetabular labrum was assessed for tears and, if present, the location and pattern were characterized.

Results Paralabral cysts were located anterosuperiorly in $56 \%$, anteriorly in $22 \%$, posterosuperiorly in $17 \%$, and anteroinferiorly in $6 \%$ of cases. The vast majority (94\%) were multilocular and filled with intra-articular contrast medium. The average dimensions were $8 \times 7 \times 11 \mathrm{~mm}$. The paralabral cyst demonstrated extracapsular extension in $72 \%$ of cases, with 39\% located between the ilium and gluteus minimus, and
\end{abstract}

O. Magerkurth · J. A. Jacobson · G. Girish · M. K. Brigido •

D. Fessell

Department of Radiology, University of Michigan,

1500 East Medical Center Drive,

Ann Arbor, MI 48109-5326, USA

O. Magerkurth $(\square)$

Department of Radiology, University Children's Hospital,

Spitalstrasse 33,

Basel, 4056, Switzerland

e-mail: dr.o.magerkurth@gmail.com

\section{A. Bedi}

Department of Orthopedic Surgery, University of Michigan, 1500 East Medical Center Drive,

Ann Arbor, MI 48109-5340, USA
$22 \%$ between the ilium and iliopsoas. Remodeling of the ilium adjacent to the cyst was observed in $50 \%$ of these cases. A labral tear was at the base of the labrum adjacent to the cyst in $78 \%$ of cases, while the tear was isolated to the body of the labrum in $22 \%$. Tears were most commonly anterosuperior $(55 \%)$ or anterior $(28 \%)$ in location.

Conclusion Our results show that paralabral cysts of the hip are most commonly located anterosuperiorly, are multilocular, fill with intra-articular contrast medium, have average dimensions up to $11 \mathrm{~mm}$, and often extend extracapsularly between muscle and bone where they may remodel the adjacent ilium.

Keywords Magnetic resonance imaging - Arthrography · Hip joint · Paralabral cysts

\section{Introduction}

Hip pain is common and is a major cause of disability secondary to limited mobility and pain, resulting in an impaired quality of life. There is a broad differential diagnosis for hip pain, which includes osteoarthritis, chondral defects, femoroacetabular impingement, stress fracture, avascular necrosis, muscle-tendon derangement, and labral tears [1]. To evaluate the cause of hip pain, imaging is a useful and critical tool to complement a careful notation of history and physical examination. MR arthrography (MRa) is specifically used to assess for internal derangement, such as labral tears, where high sensitivity and accuracy are expected given the cost and invasive nature of the imaging examination.

Acetabular labral tears are diagnosed at MR imaging and MRa when there is surface irregularity, a fluid or contrastfilled cleft, detachment, or absence of the labrum [2, 3]. While accuracy for MRa in the diagnosis of labral tear is high, with a reported sensitivity of $90 \%$ and specificity of 
91\%, evaluation with conventional MRI may be limited with a reported sensitivity of $30 \%$ and specificity of $32 \%$ [4]. Similar to paralabral cysts of the shoulder and parameniscal cysts of the knee, the presence of a paralabral cyst in the hip increases confidence that a labral tear exists [5-7]. Descriptions of paralabral cysts in the hip are limited in the literature and do not specifically detail their appearances on MRa [5-7].

In our clinical experience, we have noted variable appearances of paralabral cysts about the hip, with respect to size, location, extent, and filling with intra-articular contrast medium. The purpose of this retrospective study was to characterize the imaging appearances of paralabral cysts of the hip as seen at MR arthrography.

\section{Materials and methods}

Institutional review board approval was obtained for this retrospective study and informed consent was waived. The departmental Radiology Information System was searched from 2007 to 2010 for all patients undergoing MR arthrography of the hip. Inclusion criteria were, reported paralabral cysts or other fluid collections in the MR reports. Imaging and clinical records were also reviewed.

\section{Arthrography technique}

All patients underwent fluoroscopic-guided, intra-articular injection of contrast material prior to MR examinations performed by one of 12 musculoskeletal radiology fellows (1 year of experience) and supervised by one of 11 fellowship-trained musculoskeletal radiologists (years of experience $=4-16$ years) as part of routine patient care. A standard mixture of dilute contrast material was drawn into a 20-mL syringe, which included $0.20 \mathrm{~mL}$ of gadolinium compound (gadopentetate dimeglumine, Magnevist; Bayer Schering, Berlin, Germany), $4 \mathrm{~mL}$ of lidocaine $(10 \mathrm{mg} / \mathrm{mL}$; Lidocaine; Hospira, Lake Forest, IL, USA), $4 \mathrm{~mL}$ of bupivacaine $(5 \mathrm{mg} / \mathrm{mL}$; Marcaine; Hospira) or ropivacaine ( $5 \mathrm{mg} / \mathrm{mL}$; Naropin; APP Pharmaceuticals, Schaumburg, IL, USA), $9.8 \mathrm{~mL}$ of iopimadol 61\% (Isovue 300; Bracco Diagnostics, Princeton, NJ, USA), and $2 \mathrm{~mL}$ of triamcinolone (Kenalog 40; Bristol-Myers Squibb, Princeton, NJ, USA). Intra-articular confirmation of the 20-gauge spinal needle was confirmed with a small amount of iodinated contrast material (Isovue 300), which was followed by the dilute contrast material injection $(10-14 \mathrm{~mL})$.

MR imaging technique

Magnetic resonance images were obtained with a 1.5-T magnet (Models Excite 2 or HD; General Electric, Milwaukee,
WI, USA; Model Achieva, Philips Healthcare, Andover, MA, USA) or a 3-T magnet (Model Achieva, Philips Healthcare) in supine position by using a cardiac or body coil. The routine protocols include:

\section{5-T GE}

1. Coronal T1-weighted spin echo (SE) sequence (TR/TE: 500-600/minimum, slice thickness/gap: $3 / 1 \mathrm{~mm}$, fieldof-view [FOV]: $200 \mathrm{~mm}$, matrix: $256 \times 256$, number of excitations: 2)

2. Coronal Short $\tau$ inversion recovery (STIR; TR/TE: 4,000-5,000/26, TI: 165 , slice thickness/gap: $6 / 2 \mathrm{~mm}$, FOV: $380 \mathrm{~mm}$, matrix: $256 \times 160$, number of acquisitions: 3 )

3. Coronal oblique $\mathrm{T} 1$-weighted $\mathrm{SE}$ with fat saturation (TR/TE: 500-600/minimum; slice thickness/gap: 3/1 mm; FOV: $200 \mathrm{~mm}$; matrix: $256 \times 192$, number of excitations: 2)

4. Sagittal T1-weighted SE (TR/TE: 500-600/minimum; slice thickness/gap: 3/1 mm; FOV: $200 \mathrm{~mm}$; matrix: $256 \times 224$, number of excitations: 2 )

5. Axial T1-weighted SE (TR/TE: 500-600/minimum; slice thickness/gap: 3/1 mm; FOV: $180 \mathrm{~mm}$; matrix: $256 \times 224$, number of excitations: 2 )

6. Oblique axial T1-weighted SE (TR/TE: 500-600/minimum; slice thickness/gap: 3/1 mm; FOV: $180 \mathrm{~mm}$; matrix: $256 \times 224$, number of excitations: 2 )

\section{5-T Philips}

1. Coronal T1-weighted turbo spin echo (TSE; TR/TE: 500-650/20; TSE factor: 5; flip angle: 90; slice thickness/gap: $3 / 1 \mathrm{~mm}$; FOV (for all sequences on $1.5 \mathrm{~T}$ and 3 T Philips models feet/head $\times$ right/left $\times$ anterior/ posterior $\mathrm{mm}$ ): $200 \times 200 \times 72$; matrix: 400 ; number of excitations: 6)

2. Coronal STIR (TR/TE: shortest/30; TSE factor 12; slice thickness/gap: $6 / 1 \mathrm{~mm}$; FOV: $280 \times 355 \times 167$; matrix: 384; number of excitations: 4 )

3. Coronal oblique T1-weighted TSE with fat saturation (TR/TE: 500-650/20; TSE factor: 5; flip angle: 90; slice thickness/gap:/1 mm; FOV: $200 \times 200 \times 72$; matrix: 400; number of excitations: 6 )

4. Sagittal T1-weighted TSE (TR/TE: 500-650/20; TSE factor: 5; flip angle: 90 ; slice thickness/gap: 3/1 mm; FOV: $150 \times 150 \times 99$; matrix: 320 ; number of excitations: 6 )

5. Axial T1-weighted TSE (TR/TE: 500-650/20; TSE factor: 5; flip angle: 90 ; slice thickness/gap: 3/1 mm; FOV: $150 \times 150 \times 79$; matrix: 320 ; number of excitations: 6 )

6. Oblique axial T1-weighted TSE (TR/TE: 500-650/20; TSE factor: 5; flip angle: 90; slice thickness/gap: 
3/1 mm; FOV: $150 \times 150 \times 79$; matrix: 320 ; number of excitations: 6 )

\section{3-T Philips}

1. Coronal T1-weighted TSE (TR/TE: 500-700/20; TSE factor: 6; flip angle: 90; slice thickness/gap: $3 / 1 \mathrm{~mm}$; FOV: $200 \times 200 \times 66$; matrix: 528 ; number of excitations: 2)

2. Coronal STIR (TR/TE: shortest/30; TSE factor 15; TI: 190; slice thickness/gap: $6 / 1 \mathrm{~mm}$; FOV: $340 \times 360 \times 131$; matrix: 512; number of excitations: 1 )

3. Coronal oblique T1-weighted TSE with fat saturation (TR/TE: 500-700/20; TSE factor: 6; flip angle: 90; slice thickness/gap: $3 / 1 \mathrm{~mm}$; FOV: $300 \times 300 \times 66$; matrix: 528; number of excitations: 2)

4. Sagittal T1-weighted TSE (TR/TE: 500-700/20; TSE factor: 6; flip angle: 90; slice thickness/gap: 3/1 mm; FOV: $200 \times 66 \times 200$; matrix: 528 ; number of excitations: 2 )

5. Axial T1-weighted TSE (TR/TE: 500-700/20; TSE factor: 6; flip angle: 90 ; slice thickness/gap: $3 / 1 \mathrm{~mm}$; FOV: $65 \times 200 \times 200$; matrix: 528 ; number of excitations: 2 )

6. Oblique axial T1-weighted TSE (TR/TE: 500-700/20; TSE factor: 6; flip angle: 90; slice thickness/gap: 3/1 mm; FOV: $65 \times 200 \times 200$; matrix: 528 ; number of excitations: 2 )

\section{Analysis of images}

Magnetic resonance images were reviewed retrospectively in consensus by two fellowship-trained musculoskeletal radiologists (with 4 and 14 years' experience respectively) and one fellow (1 year's experience). Images were reviewed on a picture archiving and communication system workstation (McKesson's Horizon Medical Imaging Group, Richmond, BC, Canada) with measurements obtained using a measurement tool. As inclusion criteria for a paralabral cyst, a fluid collection had to demonstrate the following at MRa: well-defined fluid signal abnormality in direct contact with the acetabular labrum and demonstration of an adjacent labral tear shown as abnormal contrast extension into the labrum. The following measurements and observations of paralabral cysts were obtained and recorded:

1. Location: anterosuperior, anterior, anteroinferior, posterosuperior, posterior, posteroinferior relative to the hip joint

2. Configuration: simple (or unilocular) versus multilocular)

3. Contrast material filling: presence or absence of contrast signal seen within the cyst

4. Size of the cyst in maximum diameters in the anteroposterior $\times$ mediolateral $\times$ craniocaudal directions
5. Extent: intracapsular (within the joint space), paralabral: only immediately adjacent to the labrum), intramuscular, and intraosseous

6. Direction of the paralabral cyst when the cyst extended away from the labrum: anterior, posterior, superior, or inferior

7. Bone changes if in contact with paralabral cyst (none, edema, remodeling appearing as associated concavity of the adjacent cortex)

In addition, the following observations were recorded with regard to the acetabular labrum:

1. Configuration of the tear (fibrocartilage junction or labral body)

2. Location of the tear (anterosuperior, anterior, anteroinferior, posterosuperior, posterior, posteroinferior)

3. Depth of the tear (partial or full-thickness).

\section{Results}

Of the 704 patients who underwent MR arthrography from 2007 to 2010, 40 had MR reports that described the presence of a paralabral cyst or fluid collection. Of these, 22 patients had no cystic lesion, 3 had multiple geodes, 2 had an iliopsoas bursa, 1 had an obturator externa bursa, and 1 had a synovial cyst. The remaining 18 patients had a paralabral cyst as determined by consensus reading (Table 1). These 18 subjects consisted of 9 men $(50 \%)$ and 9 women $(50 \%)$ with a mean age of 38 years (range 15-57 years). With regard to cyst location relative to the acetabulum, 56\% (10 out of 18) were located anterosuperiorly (Figs. 1, 2), 22\% (4 out of 18) anteriorly, 17\% (3 out of 18) posterosuperiorly (Fig. 3), 6\% (1 out of 18) anteroinferiorly, 0\% ( 0 out of 18 ) posteriorly, and $0 \%$ ( 0 out of 18 ) posteroinferiorly. Ninety-four percent of paralabral cysts (17 out of 18) had multilocular (Figs. 1-3) and 6\% (1 out of 18) had a unilocular fluid collection. Ninety-four percent (17 out of 18) filled with intra-articular contrast material (Figs. 1-4), and 6\% (1 out of 18) did not fill. The volume of the cysts was an average of $0.39 \mathrm{~mL}$ (range: $0.01-1.7 ; 2 \mathrm{SD}=0.91$ ) with average dimensions of $8 \mathrm{~mm}$ (anteroposterior) $\times 7 \mathrm{~mm}$ (mediolateral) $\times 11 \mathrm{~mm}$ (cephalocaudad; maximum dimensions were $21 \times 16 \times$ $29 \mathrm{~mm}$ ). The paralabral cyst extended outside the capsule in $72 \%$ of cases (13 out of 18; Figs. 1-4), and was confined within the capsule in $28 \%$ (5 out of 18$)$. While none extended into bone or muscle, $39 \%$ of cysts ( 7 out of 18) were located between the ilium and gluteus minimus muscle, $22 \%$ ( 4 out of 18 ) between the ilium and iliopsoas muscle (Figs. 1, 2), and 6\% (1 out of 18) between the ilium and pectineus muscle. Remodeling of 
Table 1 Characteristics of paralabral cysts and labrum

\begin{tabular}{|c|c|c|}
\hline Characteristic & & Percentage $(n)$ \\
\hline \multirow[t]{6}{*}{ Location } & Anterosuperior & $56(10 / 18)$ \\
\hline & Anterior & $22(4 / 18)$ \\
\hline & Anteroinferior & $6(1 / 18)$ \\
\hline & Posterosuperior & $17(3 / 18)$ \\
\hline & Posterior & $0(0 / 18)$ \\
\hline & Posteroinferior & $0(0 / 18)$ \\
\hline \multirow[t]{2}{*}{ Configuration } & Simple & $6(1 / 18)$ \\
\hline & Multilocular & $94(17 / 18)$ \\
\hline \multirow[t]{2}{*}{ Contrast material filling } & Presence & $94(17 / 18)$ \\
\hline & Absence & $6(1 / 18)$ \\
\hline Size & Volume (mL) & $0.01-1.7 \mathrm{~mL}$ \\
\hline \multirow[t]{4}{*}{ Extent } & Intracapsular & $28(5 / 18)$ \\
\hline & Perilabral & $72(13 / 18)$ \\
\hline & Intramuscular & $0(0 / 18)$ \\
\hline & Intraosseous & $0(0 / 18)$ \\
\hline \multirow[t]{4}{*}{ Direction } & Anterior & $11(2 / 18)$ \\
\hline & Posterior & $0(0 / 18)$ \\
\hline & Superior & $78(14 / 18)$ \\
\hline & Inferior & $11(2 / 18)$ \\
\hline \multirow[t]{2}{*}{ Bone changes } & Remodeling & $50(9 / 18)$ \\
\hline & None & $44(8 / 18)$ \\
\hline \multirow[t]{6}{*}{ Labral tear location } & Anterosuperior & $55(10 / 18)$ \\
\hline & Anterior & $28(5 / 18)$ \\
\hline & Anteroinferior & $0(0 / 18)$ \\
\hline & Posterosuperior & $17(3 / 18)$ \\
\hline & Posterior & $0(0 / 18)$ \\
\hline & Posteroinferior & $0(0 / 18)$ \\
\hline \multirow[t]{2}{*}{ Labral tear configuration } & Fibrocartilage junction & $78(14 / 18)$ \\
\hline & Labral body & $22(4 / 18)$ \\
\hline \multirow[t]{2}{*}{ Labral tear depth } & Full-thickness & $94(17 / 18)$ \\
\hline & Partial-thickness & $6(1 / 18)$ \\
\hline
\end{tabular}

the ilium was observed in $50 \%$ of cases (9 out of 18 ; Fig. 4), absent in $44 \%$ (8 out of 18), and could not be assessed in $6 \%$ (1 out of 18) secondary to artifact. The direction of the paralabral cyst was superior in $78 \%$ (14 out of 18; Figs. 1, 2), anterior in 11\% (2 out of 18), and inferior in $11 \%$ ( 2 out of 18 ).

With regard to the labrum, a tear was identified at the junction between the base of the labrum and the adjacent hyaline articular cartilage (i.e. transitional zone cartilage) in $78 \%$ (14 out of 18) of the cases (Figs. 2, 3), while the tear was isolated to the body of the labrum in $22 \%$ (4 out of 18 ). The location of the labral tear was anterosuperior in 55\% (10 out of 18 ) (Figs. 1, 2), anterior in $28 \%$ (5 out of 18 ), and posterosuperior in $17 \%$ (3 out of 18; Fig. 3). The depth of the tear was full-thickness in $94 \%$ (17 out of 18; Figs. 2-4) and partial in $6 \%$ (1 out of 18$)$.
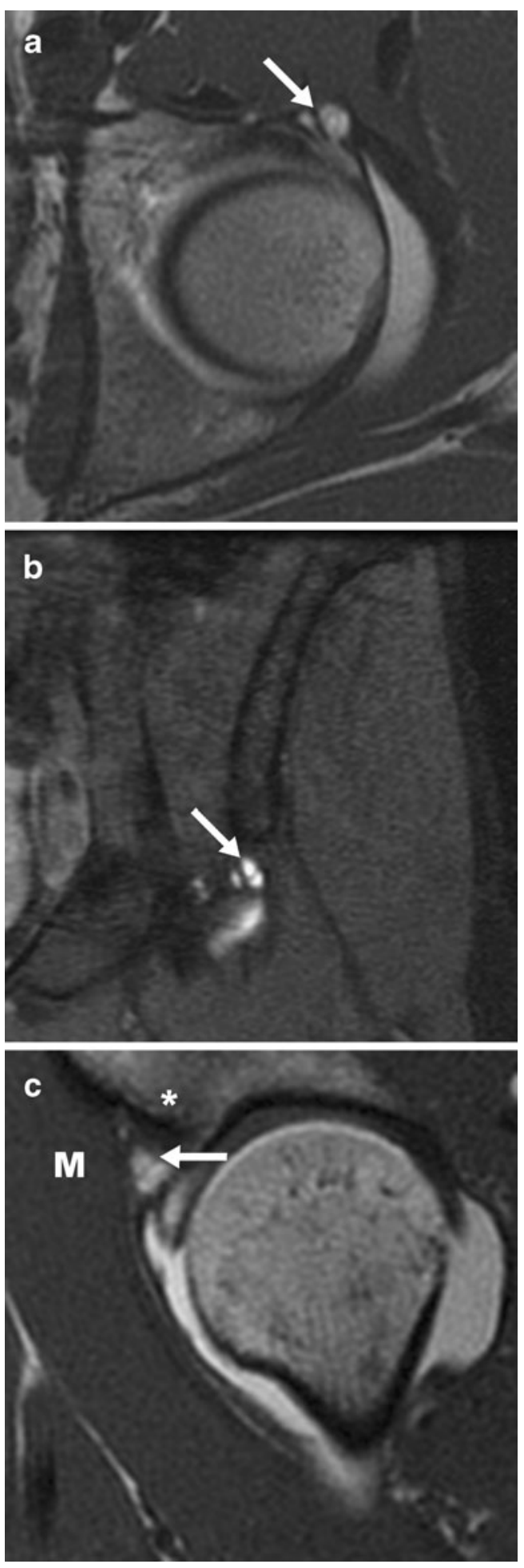

Fig. 1 A 26-year-old woman with a labral tear and paralabral cyst. a Axial T1-weighted, b coronal T1-weighted images with fat saturation, and $\mathbf{c}$ sagittal T1-weighted MR image after intra-articular administration of dilute gadolinium show a contrast material-filled, multilocular paralabral cyst (arrow) located anteriorly and superiorly, which extends superiorly between the iliac bone (asterisk) and the iliopsoas muscle $(M)$ 

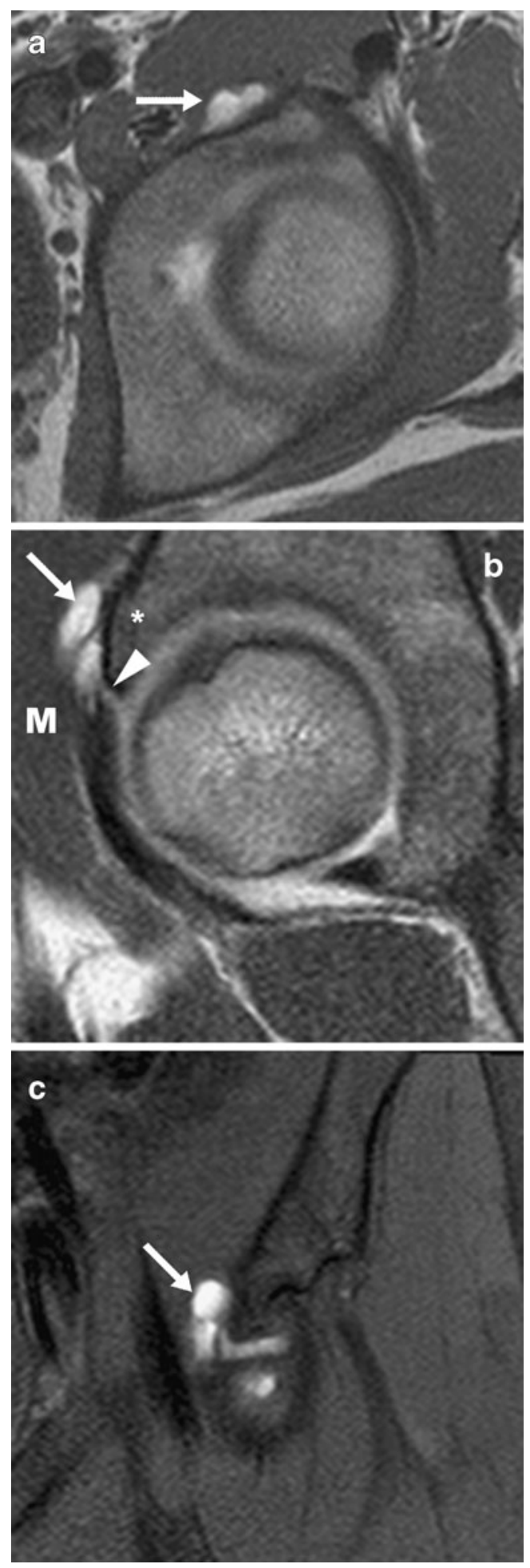

Fig. 2 A 15-year-old girl with a labral tear and paralabral cyst. a Axial T1-weighted, b sagittal T1-weighted images and c coronal T1weighted MR image with fat saturation after intra-articular administration of dilute gadolinium show a contrast material-filled, multilocular paralabral cyst (arrow) located anteriorly and superiorly, which extends superiorly between the iliac bone (asterisk) and the iliopsoas muscle $(M)$. The cyst is connected to the hip joint by an anterosuperior labral tear (arrowhead)

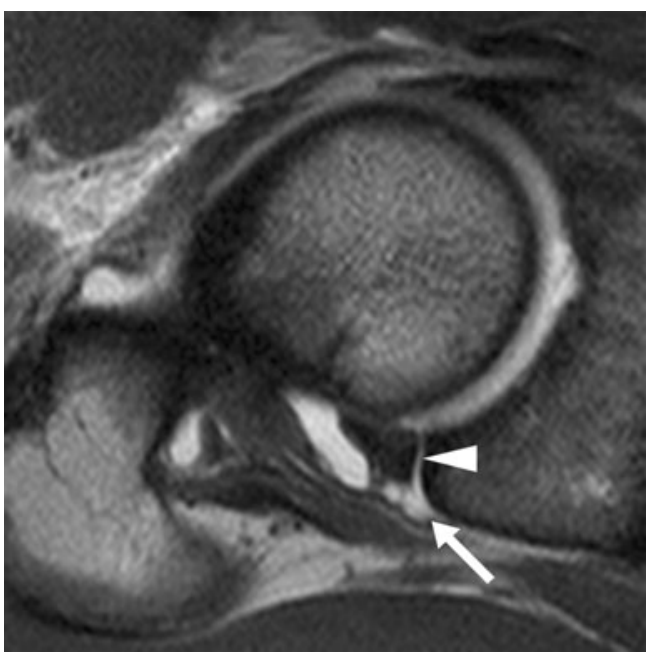

Fig. 3 A 23-year-old man with a labral tear and paralabral cyst. Axial T1-weighted MRI after intra-articular administration of dilute gadolinium shows a multilocular paralabral cyst (arrow) located posteriorly and superiorly, connected to the hip joint by a posterior labral tear (arrowhead)

\section{Discussion}

Identification of a paralabral cyst about the hip can be a clue to the presence and location of a labral tear. Our results show that paralabral cysts of the hip are most commonly anterosuperior in location, multilocular, with average dimensions up to $11 \mathrm{~mm}$, and often extend superiorly between muscle and the ilium where they may induce adjacent osseous remodeling. Paralabral cysts are highly associated with full-thickness labral tears that involve the base of the labrum at the junction with the articular cartilage (i.e. the transitional zone).

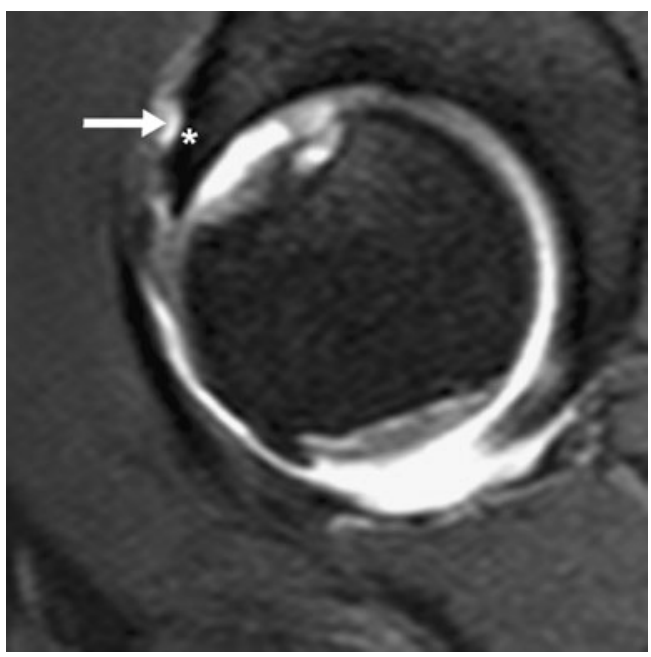

Fig. 4 A 32-year-old woman with a labral tear and paralabral cyst. Oblique sagittal T1-weighted MR image after intra-articular administration of dilute gadolinium shows a paralabral cyst (arrow) with bone erosion (asterisk) of adjacent iliac bone. Note hyaline cartilage loss of acetabulum and femoral head 
Cystic lesions of the joint may be considered to be a ganglion or synovial cyst [5]. Ganglion cysts are lined with connective tissue whereas synovial cysts are lined with synovial cells [5]. Cyst formation is considered to result from fluid extrusion from the joint space into the cyst. On imaging, ganglion or synovial cysts are indistinguishable and therefore often used synonymously [5].

It is generally accepted that parameniscal cysts in the knee are associated with meniscal tears [8-12] and paralabral cysts in the shoulder with labral tears [13]. Both require therapy, not only of the cysts, but also of the associated meniscal or labral abnormality in order to prevent recurrence of cyst formation [14]. In contrast, the characterization of paralabral cysts of the hip is limited in the literature [5-7] and restricted to association with labral tears.

The MR appearance of paralabral cysts previously has been described as a round or oval-shaped structure with fluid-like signal characteristics that may contain thin septations [5-8]. High protein content alters the signal characteristics and may result in variable imaging appearances on MR imaging [5-8]. Paralabral cysts of the hip are thought to be associated with a labral tear [5-8]. The absence of a labral tear should raise suspicion for other differential diagnoses such as atypical synovial or ganglion cyst, atypical synovitis, or possibly tumor [5-7, 15]. Although paralabral cysts are thought to communicate with the joint space via an associated labral tear, it is not documented in the peerreviewed literature how often there is filling of a paralabral cyst with intra-articular contrast material. Additionally, the extent or direction of paralabral cysts and their possible impact on surrounding soft tissue and bone has not been systematically described to date.

In our study of over $700 \mathrm{MRa}$ examinations of the hip, 18 paralabral cysts were identified. Fifty-six percent of the cysts were located anterosuperiorly followed by $22 \%$ in an anterior location. This frequency is similar to the described location of labral tears $55 \%$ anterosuperior and $28 \%$ anterior) and is consistent with the pathophysiology of paralabral cysts [5-7]. Indeed, 94\% of the paralabral cysts filled with intra-articular contrast material, which indicates a connection of the cyst with the joint space via the labral tear. In our study, $94 \%$ of paralabral cysts were multilocular. Seymour and Lloyd [16] described a similar appearance for parameniscal cysts at ultrasound and MR imaging. This finding may be explained by intermittent fluid extrusion into the cyst via a one-way valve mechanism [17].

We noted a distinctive and common pattern of extension of the paralabral cysts, where they extended beyond the labrum (perilabral; $72 \%$ ) in a superior direction $(78 \%)$ between the ilium and gluteus minimus muscle (39\%) and iliopsoas muscle $(22 \%)$. This may represent the path of minimum resistance for the fluid transferred through the labral tear into the cyst because of the pressure differences between the joint space and the cyst. Although the volume of the paralabral cysts found was small $(0.01$ to $1.7 \mathrm{~mL})$ with the largest dimension $29 \mathrm{~mm}, 50 \%$ of the patients interestingly presented with ilium remodeling. In the knee, periarticular erosions of the tibial plateau associated with parameniscal cysts are considered a rare finding $[18,19]$. Whether periacetabular erosions with paralabral cysts are more common because of higher forces applied to the hip joint or increased duration prior to diagnosis remains to be defined.

In our study, the majority of labral tears were found anterosuperiorly (55\%) and anteriorly (28\%) and are consistent with what is reported the literature [20-22]. We noticed that $78 \%$ of the tears were located at the fibrocartilage transition zone. Cashin et al. [23] showed that the fibrocartilage junction of the anterior parts of the labrum is discontinuous with the acetabular cartilage. Moreover, McCarthy et al. [24] observed a relative hypovascularity, called the "watershed zone" in the same region. Thus, the fibrocartilage junction may represent a weak point that is vulnerable to tearing and secondary herniation of synovial tissue, resulting in cyst formation. We found full-thickness tears at the fibrocartilage junction in almost all patients (94\%), supporting the hypothesis that a complete, transitional zone tear, also called detachment of the labrum, may be a key factor in the development of paralabral cysts. This finding is of clinical importance, as these tear patterns in the vascular transitional zone are typically reparable lesions [25-27]. In this regard, the results of the present study indicate that the presence of a paralabral cyst may be a favorable prognostic sign in terms of reparability of the labral tear. Of note, the single subject with a partialthickness labral tear by MRa criteria may relate to scar tissue or partial healing of a full-thickness tear that inhibited fullthickness contrast extension.

The limitations of our study are its retrospective design and absence of correlation with clinical symptoms or intraoperative surgical findings. In our study the presence or absence of paralabral cysts is not mentioned, possibly because of the relatively small size and the location, which may be difficult to assess during arthroscopy. However, the study utilized a large series of over $700 \mathrm{MRa}$. In addition, paralabral cysts were not compared with other cysts or fluid collections around the hip. The concentration of gadolinium in our series (approximately $5 \mathrm{mmol} / \mathrm{L}$ ) was higher than recommended (up to $3.4 \mathrm{mmol} / \mathrm{L}$ ), which is another limitation [28]. Lastly, the criteria for paralabral cysts included an adjacent labral tear. It is possible that a paralabral cyst associated with a healed labral tear could be excluded; however, the presence of labral tear was used as an inclusion criterion to ensure that the cyst was indeed a paralabral cyst given that surgical confirmation was not possible. 
In conclusion, paralabral cysts around the hip are most commonly anterosuperior in location, multilocular, fill with intra-articular contrast material, and are associated with peripheral, potentially reparable tears at the base of the labrum. They often extend superiorly between the gluteus minimus and ilium and may demonstrate adjacent osseous remodeling. Accurate identification of a paralabral cyst around the hip joint is a clue to presence and location of a full-thickness labral tear at the fibrocartilage junction, and may be a favorable prognostic finding with regard to the reparability of the labral injury. In addition, familiarity with the appearances of paralabral cysts at MR arthrography may minimize confusion with other cystic lesions around the hip.

\section{References}

1. Hodnett PA, Shelly MJ, MacMahon PJ, Kavanagh EC, Eustace SJ. MR imaging of overuse injuries of the hip. Magn Reson Imaging Clin N Am. 2009;17(4):667-79. vi.

2. Hodler J, Yu JS, Goodwin D, Haghighi P, Trudell D, Resnick D. MR arthrography of the hip: improved imaging of the acetabular labrum with histologic correlation in cadavers. AJR Am J Roentgenol. 1995;165(4):887-91.

3. Petersilge CA, Haque MA, Petersilge WJ, Lewin JS, Lieberman JM, Buly R. Acetabular labral tears: evaluation with MR arthrography. Radiology. 1996;200(1):231-5.

4. Czerny C, Hofmann S, Neuhold A, Tschauner C, Engel A, Recht MP, et al. Lesions of the acetabular labrum: accuracy of MR imaging and MR arthrography in detection and staging. Radiology. 1996;200(1):225-30.

5. Haller J, Resnick D, Greenway G, Chevrot A, Murray W, Haghighi $\mathrm{P}$, et al. Juxtaacetabular ganglionic (or synovial) cysts: CT and MR features. J Comput Assist Tomogr. 1989;13(6):976-83.

6. Magee T, Hinson G. Association of paralabral cysts with acetabular disorders. AJR Am J Roentgenol. 2000;174(5):1381-4.

7. Schnarkowski P, Steinbach LS, Tirman PF, Peterfy CG, Genant HK. Magnetic resonance imaging of labral cysts of the hip. Skeletal Radiol. 1996;25(8):733-7.

8. Campbell SE, Sanders TG, Morrison WB. MR imaging of meniscal cysts: incidence, location, and clinical significance. AJR Am J Roentgenol. 2001;177(2):409-13.

9. Hulet C, Souquet D, Alexandre P, Locker B, Beguin J, Vielpeau C. Arthroscopic treatment of 105 lateral meniscal cysts with 5-year average follow-up. Arthroscopy. 2004;20(8):831-6.

10. Ryu RK, Ting AJ. Arthroscopic treatment of meniscal cysts. Arthroscopy. 1993;9(5):591-5.
11. Tasker AD, Ostlere SJ. Relative incidence and morphology of lateral and medial meniscal cysts detected by magnetic resonance imaging. Clin Radiol. 1995;50(11):778-81.

12. Tyson LL, Daughters Jr TC, Ryu RK, Crues 3rd JV. MRI appearance of meniscal cysts. Skeletal Radiol. 1995;24(6):421-4.

13. Tirman PF, Feller JF, Janzen DL, Peterfy CG, Bergman AG. Association of glenoid labral cysts with labral tears and glenohumeral instability: radiologic findings and clinical significance. Radiology. 1994;190(3):653-8

14. Reagan WD, McConkey JP, Loomer RL, Davidson RG. Cysts of the lateral meniscus: arthroscopy versus arthroscopy plus open cystectomy. Arthroscopy. 1989;5(4):274-81.

15. Sherman PM, Matchette MW, Sanders TG, Parsons TW. Acetabular paralabral cyst: an uncommon cause of sciatica. Skeletal Radiol. 2003;32(2):90-4.

16. Seymour R, Lloyd DC. Sonographic appearances of meniscal cysts. J Clin Ultrasound. 1998;26(1):15-20.

17. Stuhler T. [Functional stenosis. Current theory of the pathogenesis of meniscal ganglion]. Z Orthop Ihre Grenzgeb. 1984;122(3):32934.

18. Blair TR, Schweitzer M, Resnick D. Meniscal cysts causing bone erosion: retrospective analysis of seven cases. Clin Imaging. 1999;23(2):134-8.

19. Juhng SK, Lenchik L, Won JJ. Tibial plateau erosions associated with lateral meniscal cysts. Skeletal Radiol. 1998;27 (5):288-90.

20. Blankenbaker DG, De Smet AA, Keene JS, Fine JP. Classification and localization of acetabular labral tears. Skeletal Radiol. 2007;36 (5):391-7.

21. Fitzgerald Jr RH. Acetabular labrum tears. Diagnosis and treatment. Clin Orthop Relat Res. 1995;311:60-8.

22. Lage LA, Patel JV, Villar RN. The acetabular labral tear: an arthroscopic classification. Arthroscopy. 1996;12(3):269-72.

23. Cashin M, Uhthoff H, O'Neill M, Beaulé PE. Embryology of the acetabular labral-chondral complex. J Bone Joint Surg Br. 2008;90 (8):1019-24.

24. McCarthy JC, Noble PC, Schuck MR, Wright J, Lee J. The watershed labral lesion: its relationship to early arthritis of the hip. J Arthroplasty. 2001;16(8 Suppl 1):81-7.

25. Kelly BT, Shapiro GS, Digiovanni CW, Buly RL, Potter HG, Hannafin JA. Vascularity of the hip labrum: a cadaveric investigation. Arthroscopy. 2005;21(1):3-11.

26. Petersen W, Petersen F, Tillmann B. Structure and vascularization of the acetabular labrum with regard to the pathogenesis and healing of labral lesions. Arch Orthop Trauma Surg. 2003;123 (6):283-8.

27. Philippon MJ, Arnoczky SP, Torrie A. Arthroscopic repair of the acetabular labrum: a histologic assessment of healing in an ovine model. Arthroscopy. 2007;23(4):376-80.

28. Andreisek G, Froehlick JM, Hodler J, et al. Direct MR arthrography at 1.5 and $3.0 \mathrm{~T}$ : signal dependence on gadolinium and iodine concentrations - phantom study. Radiology. 2008;247:706-16. 